\title{
超高产栽培杂交中籼稻的生长发育特性
}

\author{
潘圣刚 ${ }^{1,2}$ 黄胜奇 ${ }^{1}$ 张 帆 ${ }^{1}$ 汪金平 ${ }^{1}$ 蔡明历 ${ }^{1}$ 曹凑贵 ${ }^{1, *}$ \\ 唐湘如 ${ }^{2}$ 黎国喜 ${ }^{2}$
}

${ }^{1}$ 华中农业大学作物栽培与生理生态研究中心, 湖北武汉 $430070{ }^{2}$ 华南农业大学农学院, 广东广州 510642

摘 要: 以 5 个杂交中籼稻品种(含品系)扬两优 6 号、P88S/747、珞优 8 号、珞优 234 和天两优 2 号为材料, 研究大 田条件下超高产水平(产量 $\geqslant 12.0 \mathrm{t} \mathrm{hm}^{-2}$ )的物质生产、产量构成及养分吸收特性。试验结果表明, 与高产水稻(产量 $\geqslant 9.0 \mathrm{t} \mathrm{hm}$ ) 相比, 超高产水稻具有以下特征, 幼穗分化期、齐穗期和灌浆结实期(齐穗后 $10 \mathrm{~d}$ ) LAI 大, 分别为 6.5 7.2、8.5 8.9 和 6.5 7.0; 齐穗期的高效叶面积比率高, 为 60.0\% 66.5\%; 齐穗期、灌浆期和成熟期积累较多的干 物质, 分别为 13.5 15.0、15.0 16.0 和 25.0 28.0 $\mathrm{t} \mathrm{hm}^{-2}$; 分藍盛期对氮 $(\mathrm{N})$ 、磷 $(\mathrm{P})$ 、钾 $(\mathrm{K})$ 吸收利用优势不明显, 而幼 穗分化期、齐穗期和成熟期对 N、P、K 吸收利用高而且积累速度快。此外, 具有穗数多(有效穗数介于 $250 \times 10^{4}$ $\sim 290 \times 10^{4}$ 穗 $\mathrm{hm}^{-2}$ )、结实率高( $\left.88.2 \% ~ 92.3 \%\right) 、 千$ 粒重大(29.0 31.0 g)的特点。

关键词: 杂交中籼稻; 超高产; 叶面积指数; 生物量; 养分吸收

\section{Growth and Development Characteristics of Super-High-Yielding Mid-Season Indica Hybrid Rice}

PAN Sheng-Gang ${ }^{1,2}$, HUANG Sheng-Qi ${ }^{1}$, ZHANG Fan ${ }^{1}$, WANG Jing-Ping ${ }^{1}$, CAI Ming-Li ${ }^{1}$, CAO Cou-Gui ${ }^{1, *}$, TANG Xiang- $\mathrm{Ru}^{2}$, and LI Guo-Xi ${ }^{2}$

${ }^{1}$ Crop Production and Physiology Center, Huazhong Agricultural University, Wuhan 430070, China; ${ }^{2}$ College of Agriculture, South China Agricultural University, Guangzhou 510642, China

\begin{abstract}
In order to study the characteristics of super high yielding (yield $\geq 12.0 \mathrm{t} \mathrm{ha}^{-1}$ ) of mid-season indica hybrid rice cultivars in nutrition absorption, dry matter production and yield formation, we grew five rice cultivars (including lines), Yangliangyou 6, P88S/747, Luoyou 8, Luoyou 234, and Tianliangyou 2 in paddy fields. The leaf area index (LAI) at panicle initiation stage, heading stage and grain filling stage of super-high-yield rice was significantly higher than that of the high-yield rice (CK, Yangliangyou 6, grain yield $\geq 9.0 \mathrm{tha}^{-1}$ ), which was in the range of 6.5-7.2, 8.5-8.9, and 6.5-7.0, respectively. The ratio of high effective leaf area to total leaf area at the heading stage was higher than that of CK, which was in the range of $60.0 \%-66.5 \%$. Super high yielding rice had more dry matter accumulation than CK at the heading stage, grain filling stage and maturity stage, which was in the range of 13.5-15.0, 15.0-16.0, and 25.0-28.0 $\mathrm{t} \mathrm{ha}^{-1}$, respectively. Super-high-yield rice did not show any advantage in the absorption of N, P, and K at mid-tillering stage compared with CK, however, had noticeable advantage in that at panicle initiation stage, heading stage and maturity stage. Furthermore, super high yield rice had more productive panicles, higher seed setting rate and grain weight in comparison with CK, which were in the range of $250 \times 10^{4}-290 \times 10^{4}$ panicles per ha, $88.2 \%-92.3 \%$ and 29.0-31.0 g, respectively.
\end{abstract}

Keywords: Mid-season indica hybrid rice; Super-high-yield; Leaf area index; Biomass; Nutrition absorption

水稻是我国最重要的粮食作物之一, 全国水稻 种植面积约占粮食作物总面积的 $30 \%$, 产量接近粮 食总产量的一半 ${ }^{[1]}$ 。随着工业化进程的推进, 在耕地 面积不可能增大的情况下, 提高水稻的单产, 是增
加水稻总产量, 保障国家粮食安全的重要措施。因 此, 最大限度地挖掘作物品种的遗传潜力和提高栽 培管理技术水平, 一直是农业工作者的研究重点 ${ }^{[2-4]}$ 。 1996 年, 农业部正式启动“中国超级稻”计划 ${ }^{[5]}$ 。目前,

本研究由国家科技支撑计划项目(2011BAD16B02)资助。

“通讯作者(Corresponding author): 曹凑贵, E-mail: ccgui@mail.hzau.edu.cn

第一作者联系方式: E-mail: panshenggang@scau.edu.cn

Received(收稿日期): 2010-08-21; Accepted(接受日期): 2010-12-12. 
国内外超级稻育种和栽培已取得重要进展, 育成一 批在生产上推广应用的超级稻品种或杂交组合, 涌 现出一些水稻超高产典型, 形成了一些超高产栽培 模式。1989年, 国际水稻研究所从理想株型角度出发, 启动了“新株型育种计划”, 并从农艺性状方面对新 株型提出了具体要求, 产量要求在菲律宾旱季种植 可达到 $13 \mathrm{t} \mathrm{hm}^{-2[6]}$ 。江苏省凌启鸿等 ${ }^{[7]}$, 提出了水稻 叶龄模式化栽培技术, 四川省马均和陶诗顺等 ${ }^{[8]}$ 提出 了“杂交中稻超多蓝壮秧超稀高产栽培技术”，广东 省钟旭华等 ${ }^{[9]}$ 提出的“控总氮含量和基萻肥比例、控 高峰苗、控病虫害”的“三控”栽培法, 湖南省刍应斌 等 ${ }^{[10]}$ 提出的定目标产量、定群体指标、定技术规范 “三定”栽培法。这些超高产栽培技术都是在特定的 生态环境条件下形成的, 适应当地生态条件下(或相 似生态环境)的水稻生长, 对指导当地的水稻高产栽 培具有较大的推动作用。然而, 湖北省作为全国重 要的水稻种植大省之一, 具有独特的气候条件和自 然资源, 而中稻又是湖北省种植面积最大的粮食作 物。因此, 搞好湖北省的中稻生产对湖北省的粮食 丰产乃至国家的粮食安全都起到极其重要的作用。 本研究以多个品种为材料, 连续两年研究了杂交中 籼稻超高产群体 $\left(12 \mathrm{t} \mathrm{hm}^{-2}\right)$ 的生长发育特性, 并提出 与之相适宜的超高产栽培模式, 期望为水稻超高产 育种与栽培提供参考。

\section{1 材料与方法}

\section{1 试验田概况}

华中农业大学随州试验站(均川镇幸福村 4 组) 处湿润的亚热带季风气候区, 水稻生长季节日平均 温度为 $24.5^{\circ} \mathrm{C}$, 降雨量为 $650 \mathrm{~mm}$ 。试验地前茬作物 为小麦, 供试土壤为水稻土, 耕作层土壤 $\mathrm{pH} 5.53$, 有机质 $24.15 \mathrm{~g} \mathrm{~kg}^{-1}$ 、全氮 $1.14 \mathrm{~g} \mathrm{~kg}^{-1} 、 \mathrm{NH}_{4}{ }^{+}-\mathrm{N} 0.58$ $\mathrm{mg} \mathrm{kg}^{-1} 、 \mathrm{NO}_{3}{ }^{-}-\mathrm{N} 13.22 \mathrm{mg} \mathrm{kg}^{-1}$ 、速效磷 $43.88 \mathrm{mg} \mathrm{kg}^{-1}$ 、 速效钾 $46.65 \mathrm{mg} \mathrm{kg}^{-1}$ 。

\section{2 试验设计}

2008 年供试水稻品种为扬两优 6 号、P88S/747 和珞优 8 号, 2009 年供试水稻品种为扬两优 6 号、 珞优 8 号、两优 234 和天两优 2 号, 均由农业部华 中农业大学作物生理生态与栽培重点开放试验室提 供。2008 年 4 月 12 日播种，两段育秧，6月 3 日移 栽。2009 年 4 月 15 日播种，两段育种，6月 2 日移 栽。两年的大田栽插密度均为 $2.7 \times 10^{5}$ 萖 $\mathrm{hm}^{-2}$, 宽 窄行栽插, 窄行 $20 \mathrm{~cm}$, 宽行 $33.3 \mathrm{~cm}$, 株距 $14.0 \mathrm{~cm}$,
每穴插 2 株。大田施氮 $240 \mathrm{~kg} \mathrm{~N} \mathrm{hm}^{-2}$ ，基肥：菜肥： 穗粒肥 $=3 ： 2 ： 5$ 。基肥，在移栽前 $1 \mathrm{~d}$ 施入; 分蓝 肥, 于移栽后 $10 \mathrm{~d}$ 施入; 穗粒肥, 于移栽后 $36 \mathrm{~d}$ 施 入。另外, 钾肥 $\left(\mathrm{K}_{2} \mathrm{O}\right) 330 \mathrm{~kg} \mathrm{hm}^{-2}$, 按基肥: 幼穗分 化肥 = 5：5 施入; 磷肥 $\left(\mathrm{P}_{2} \mathrm{O}_{5}\right) 120 \mathrm{~kg} \mathrm{hm}^{-2}$, 作底肥 一次性施入。以尿素、过磷酸钙及氯化钾分别作为 氮肥、磷肥和钾肥。水分管理模式为干湿交替灌溉, 其他管理模式同当地的高产栽培, 及时防治病虫害。

在超高产试验田附近选择 1 个普通的高产(产量 $>9.0 \mathrm{t} \mathrm{hm}^{-2}$ )田块(面积>0.11 $\mathrm{hm}^{2}$ ) 作为对照 (CK), 按 照对角线取样法田间取样 3 点, 求其平均值。对照 田的土壤质地和养分水平同超高产试验田。选用品 种为扬两优 6 号, 播种和收割日期同超高产栽培。 育秧方式、栽插密度和肥水管理等均同当地的高产 栽培, 即湿润育秧, 积龄为 $40 \mathrm{~d}$, 等株行距栽插, 大 田栽培密度为 $2.1 \times 10^{5}$ 䒚 $\mathrm{hm}^{-2}$, 株行距为 14.29 $\mathrm{cm} \times 33.30 \mathrm{~cm}$, 每熦插 2 株。总施氮量为 $195 \mathrm{~kg} \mathrm{~N}$ $\mathrm{hm}^{-2}$, 按基肥：分葲肥：穗粒肥 $=4 ： 3 ： 3$, 施肥时 期同超高产试验田。另外, 钾肥 $\left(\mathrm{K}_{2} \mathrm{O}\right) 60 \mathrm{~kg} \mathrm{hm}^{-2}$, 磷 肥 $\left(\mathrm{P}_{2} \mathrm{O}_{5}\right) 60 \mathrm{~kg} \mathrm{hm}^{-2}$, 均用作基肥一次性施入。以尿 素、过磷酸钙及氯化钾分别作为氮肥、磷肥和钾肥。

1.3 测定项目及方法

1.3.1 茎藥动态 在每小区第四行定点连续调查 15 萝, 记载分藍动态变化情况, 每 $4 \mathrm{~d}$ 调查一次。

1.3.2 叶面积指数测定在水稻生长的关键生育 时期(分藍盛期、幼穗分化期、齐穗期和灌浆期), 每 小区取代表性植株 4 熦，分茎鞘、叶、穗，测定部分 叶片的长和宽, 用长 $\times$ 宽 $\times$ 校正系数 0.75 , 求出叶面 积, 将已测叶面积的叶片在 $105^{\circ} \mathrm{C}$ 杀青 $30 \mathrm{~min}$, 再转 至 $80^{\circ} \mathrm{C}$ 烘干称重, 采用重量法计算总叶面积, 换算 求出叶面积指数。

1.3.3 生物量测定 结合着叶面积指数的测定, 把水稻植株的茎、鞘、叶、穗分开, 于 $105^{\circ} \mathrm{C}$ 烘箱中 杀青 $30 \mathrm{~min}$, 在 $80^{\circ} \mathrm{C}$ 下烘干至恒重, 冷却至室温后 用 $1 / 1000$ 电子天平称取干重。

1.3.4 氮、磷、钾养分测定结合着生物量测定, 把称重后的水稻不同器官(茎鞘、叶片和穗)单独粉碎, 采用凯氏定氮法测定植株全氮含量 ${ }^{[11]}$ ，火焰光度计 法测定植株全钾含量 ${ }^{[11]}$, 钼锑抗比色法测定植株全 磷含量 ${ }^{[11]}$ 。氮磷钾素积累总量通过不同生育时期各 器官的氮磷钾含量乘以其生物量获得。

1.3.5 产量及其构成因子产量构成因子按照前 人 $^{[12]}$ 方法测得, 由专家组测定产量。即测量一定面 
积田块, 用收割机现场收割, 称重除杂, 并折合成 干谷(含水量为 $13.5 \%$ )重量。

\section{2 结果与分析}

\section{1 产量及其构成因子}

表 1 表明, 连续 2 年超高产栽培的各个水稻品 种的收获产量均超过 $12.0 \mathrm{t} \mathrm{hm}^{-2}$, 其中, 2008 年 P88S/747 品种和 2009 年扬两优 6 号品种的产量均超 过 $13.0 \mathrm{t} \mathrm{hm}^{-2}$, 分别为 $13.21 \mathrm{t} \mathrm{hm}^{-2}$ 和 $13.62 \mathrm{t} \mathrm{hm}^{-2}$ 。 两年超高产栽培水稻平均产量为 $12.75 \mathrm{t} \mathrm{hm}^{-2}$, 较对 照 $\left(9.32 \mathrm{t} \mathrm{hm}^{-2}\right)$ 增加了 $36.80 \%$, 超出了相对产量较对 照增产 $15 \%$ 的超高产指标 ${ }^{[2]}$ 。尽管超高产栽培水稻 的高峰苗比对照多, 且其成穗率(68.0\%)显著高于对 照, 因此, 超高产栽培水稻的单位面积总穗数显著 高于对照, 其值大于 $250 \times 10^{4}$ 穗 $\mathrm{hm}^{-2}$, 而对照仅为 $200 \times 10^{4} \sim 220 \times 10^{4}$ 穗 $\mathrm{hm}^{-2}$ 。超高产水稻的结实率均 大于 $88.2 \%$, 显著高于对照( $86.0 \%)$, 而超高产栽培 水稻的每穗总粒数和千粒重与对照差异不显著(仅 有个别品种差异达到显著水平), 这也说明增加水稻 单位面积穗数和提高结实率是实现水稻超高产栽培 的关键。

\section{2 茎萻动态}

水稻茎菜数的动态变化影响着高峰苗的多少和 最终成穗率的高低。图 1 和图 2 表明, 水稻每揽茎
菜数呈现先快速增加而后降低, 最后趋于稳定的态 势。2008 年, P88S/747、珞优 8 号和扬两优 6 号返青 期每揽茎竪数分别为 $7.35 、 8.59$ 和 7.06 个 莜 ${ }^{-1}$, 高 峰苗分别为 $14.73 、 14.36$ 和 13.88 个 熦 ${ }^{-1}$, 而对照 返青期每萖茎藮数为 6.30 个 莜 ${ }^{-1}$ 、高峰值为 16.5 个 萝 ${ }^{-1}$ 。2009 年, 扬两优 6 号、两优 234、天两优 2 号、珞优 8 号返青期每萖茎菜数分别为 7.36、7.88、 7.21 和 8.35 个 莜 ${ }^{-1}$, 高峰苗分别为 $13.35 、 13.78$ 、 15.27 和 14.02 个 莧 ${ }^{-1}$, 而对照返青期每萖茎菜数为 5.22 个 萝 ${ }^{-1}$, 高峰苗为 16.66 个 萖 ${ }^{-1}$ 。

超高产栽培水稻的茎藍数, 返青期约为最终成 穗数的 $75 \%$, 开始拔节时达到高峰值, 约为最终成 穗数的 1.45 倍(2008 年)和 1.28 倍(2009 年); 此后缓 慢下降, 抽穗期等于或稍多于最终成穗数。最终成 穗率约为 66.7\% (2008 年)和 74.0\% (2009 年), 而对 照田块水稻的成穗率约为 58.5\% (2008 年)和 68.0\% (2009 年)。

\section{3 叶面积指数}

从图 3 和图 4 可以看出, 超高产栽培水稻的叶 面积指数(LAI)在生长前期(从分菜期至孕穗期)和对 照基本持平，生长中后期(齐穗至灌浆期)则明显高 于对照。超高产栽培水稻全生育期叶面积指数的变 化特点是, 分乑盛期为 3.0 3.5 左右, 幼穗分化期为 6.5 7.2 左右, 齐穗期为 8.5 8.9 左右, 灌浆期(齐穗

表 1 栽培模式对不同水稻品种产量及其构成因子的影响

Table 1 Effects of cultivation mode on yield and its components in different cultivars of rice

\begin{tabular}{|c|c|c|c|c|c|c|c|c|c|}
\hline \multirow{2}{*}{$\begin{array}{c}\text { 产量及其构成因子 } \\
\text { Yield and its } \\
\text { components }\end{array}$} & \multicolumn{4}{|c|}{2008} & \multicolumn{5}{|c|}{2009} \\
\hline & $\begin{array}{c}\text { 扬两优 } 6 \text { 号 } \\
\text { YLY6 }\end{array}$ & $\begin{array}{c}\text { 珞优 } 8 \text { 号 } \\
\text { LY8 }\end{array}$ & P88S/747 & CK & $\begin{array}{c}\text { 扬两优 } 6 \text { 号 } \\
\text { YLY6 }\end{array}$ & $\begin{array}{c}\text { 珞优 } 8 \text { 号 } \\
\text { LY8 }\end{array}$ & $\begin{array}{c}\text { 天两优 } 2 \text { 号 } \\
\text { TLY2 }\end{array}$ & $\begin{array}{c}\text { 两优 } 234 \\
\text { LY234 }\end{array}$ & CK \\
\hline $\begin{array}{l}\text { 面积 } \\
\text { Area }\left(h^{2}\right) \\
\text { 高峰苗 }\end{array}$ & 0.28 & 0.19 & 0.22 & 0.14 & 0.66 & 0.28 & 0.25 & 0.27 & 0.12 \\
\hline $\begin{array}{l}\text { Population peak } \\
\left(\times 10^{4} \mathrm{hm}^{-2}\right) \\
\text { 总穗数 }\end{array}$ & 374.7 a & $387.8 \mathrm{a}$ & 397.7 a & $346.5 \mathrm{~b}$ & $360.5 \mathrm{~b}$ & $378.5 \mathrm{~b}$ & $412.4 \mathrm{a}$ & $372.0 \mathrm{~b}$ & $349.8 \mathrm{~b}$ \\
\hline $\begin{array}{l}\text { Total panicle } \\
\left(\times 10^{4} \mathrm{hm}^{-2}\right)\end{array}$ & 252.3 a & $273.0 \mathrm{a}$ & $258.0 \mathrm{a}$ & 202.8 b & $279.6 \mathrm{~b}$ & 292.5 a & $256.5 \mathrm{~b}$ & $267.0 \mathrm{~b}$ & 220.8 c \\
\hline $\begin{array}{l}\text { 成穗率 } \\
\text { Productive panicle (\%) }\end{array}$ & 67.33 a & 70.41 a & 64.88 a & $58.53 \mathrm{~b}$ & 77.57 a & 77.29 a & $62.20 \mathrm{~b}$ & 71.77 a & $63.12 \mathrm{~b}$ \\
\hline $\begin{array}{l}\text { 总粒数/穗 } \\
\text { Spikelets per panicle }\end{array}$ & $192.00 \mathrm{a}$ & 183.60 a & $185.00 \mathrm{a}$ & 184.57 a & $210.00 \mathrm{a}$ & $187.80 \mathrm{~b}$ & $197.00 \mathrm{ab}$ & $186.00 \mathrm{~b}$ & $188.23 \mathrm{~b}$ \\
\hline $\begin{array}{l}\text { 结实率 } \\
\text { Seed setting rate (\%) }\end{array}$ & $92.10 \mathrm{a}$ & $92.30 \mathrm{a}$ & $92.20 \mathrm{a}$ & 86.81 b & $90.00 \mathrm{a}$ & $89.80 \mathrm{a}$ & $88.20 \mathrm{a}$ & $91.70 \mathrm{a}$ & $85.27 \mathrm{~b}$ \\
\hline $\begin{array}{l}\text { 千粒重 } \\
\text { 1000-seed weight (g) }\end{array}$ & $29.50 \mathrm{~b}$ & $29.10 \mathrm{~b}$ & $31.00 \mathrm{a}$ & $28.88 \mathrm{~b}$ & $29.00 \mathrm{a}$ & 28.80 a & 29.20 a & 29.10 a & $28.96 \mathrm{a}$ \\
\hline $\begin{array}{l}\text { 收获产量 } \\
\text { Harvest yield }\left(\mathrm{t} \mathrm{hm}^{-2}\right)\end{array}$ & 12.48 a & $12.52 \mathrm{a}$ & $13.21 \mathrm{a}$ & $9.09 \mathrm{~b}$ & $13.62 \mathrm{a}$ & $12.83 \mathrm{ab}$ & $12.17 \mathrm{~b}$ & $12.43 \mathrm{ab}$ & $9.54 \mathrm{c}$ \\
\hline
\end{tabular}

标以不同小写字母的值差异达 $5 \%$ 显著水平。

Values followed by different letters are significantly different at 5\% probability level. YLY6: Yangliangyou 6; LY8: Luoyou 8; TLY2: Tianliangyou 2; LY234: Luoyou 234. 


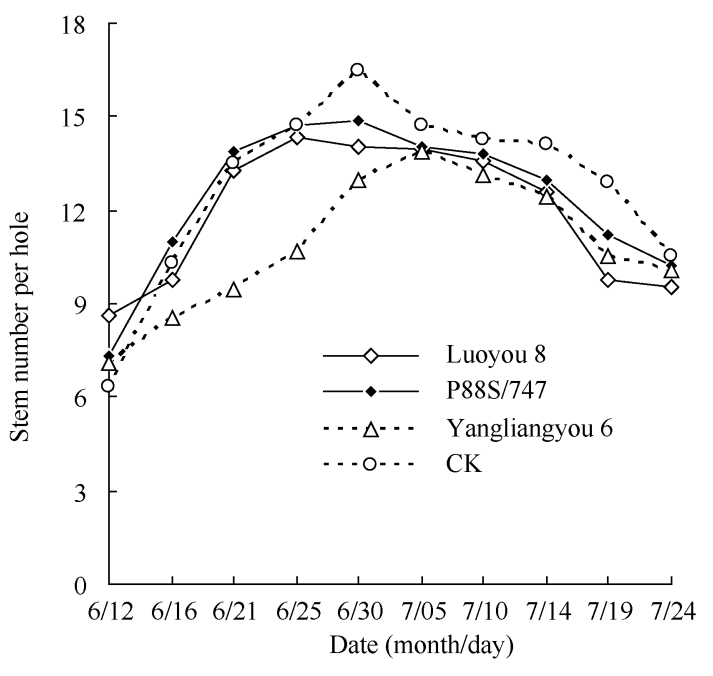

图 12008 年不同水稻品种穴茎藍数动态变化

Fig. 1 Stem number per hole in different cultivars of rice in 2008

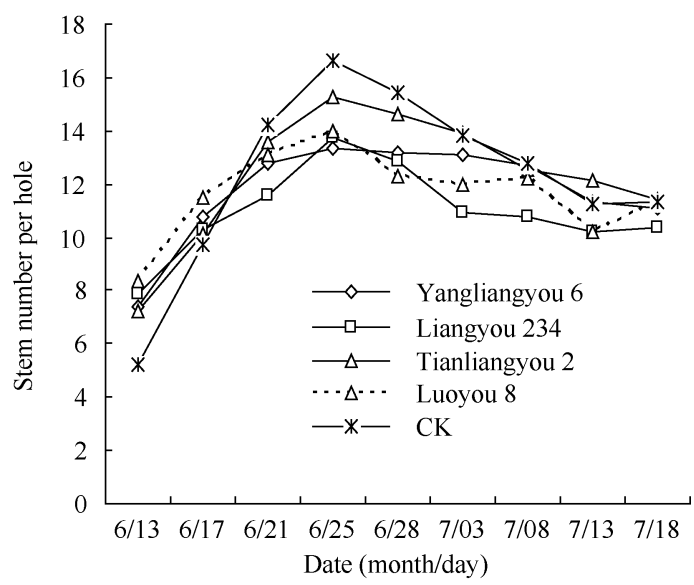

图 22009 年不同水稻品种穴茎藍数动态变化

Fig. 2 Stem number per hole in different cultivars of rice in 2009

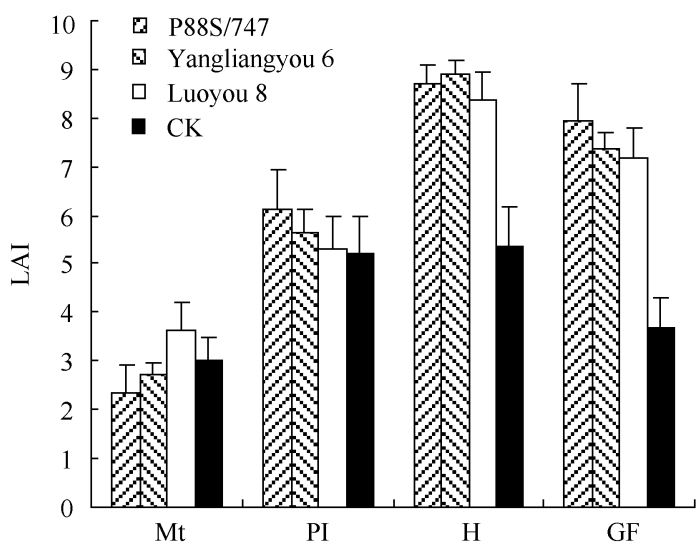

图 32008 年不同生育时期水稻叶面积指数

Fig. 3 Leaf area index (LAI) at the growth stage in rice in 2008 Mt: 分蒏盛期; PI: 幼穗分化期; H: 齐穗期; GF：灌浆结实期。

Mt: mid-tillering stage; PI: panicle initiation stage; $\mathrm{H}$ : heading stage; GF: grain filling stage.

后 10 d)为 $6.5 \sim 7.0$ 左右, 成熟期仍有较大的叶面积 指数。齐穗期的高效叶面积比率(上三叶面积占有效
叶面积的比率)为 $60.0 \%$ 66.5\%, 而对照仅为 $50.6 \%$, 说明超高产栽培水稻具有较多的叶“源”。

\section{4 生物量}

超高产栽培水稻和对照在不同生育时期所积累 的总生物量存在较大差异。从图 5 和图 6 可以看出, 超高产栽培水稻的总生物量在分薛期和幼穗分化期 与对照接近，进入幼穗分化期以后，显著高于对照。 其总生物量 $\left(\mathrm{t} \mathrm{hm^{-2 }}\right)$, 分薛期为 2.1 2.5, 幼穗分化期 为 8.5 10.0, 齐穗期为 13.5 15.0, 灌浆期 15.0 16.0, 成熟期为 25.0 28.0。齐穗期的生物量为成熟期总生 物量的 $60 \%$ 左右, 齐穗至成熟期所积累的总生物量 占成熟期总生物量的 $40 \%$ 。而对照总生物量, 分藮 期为 $1.8 \sim 2.0$, 幼穗分化期为 $7.5 \sim 8.5$, 齐穗期为

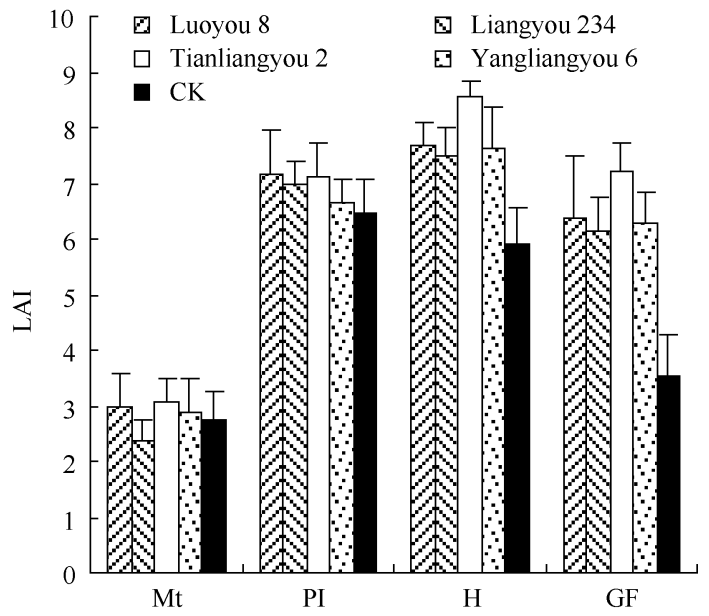

图 42009 年不同生育时期水稻叶面积指数 Fig. 4 Leaf area index (LAI) at the growth stage in rice in 2009 $\mathrm{Mt}$ : 分藍盛期; PI：幼穗分化期; H: 齐穗期; GF：灌浆结实期。 Mt: mid-tillering stage; PI: panicle initiation stage; $\mathrm{H}$ : heading stage; GF: grain filling stage.

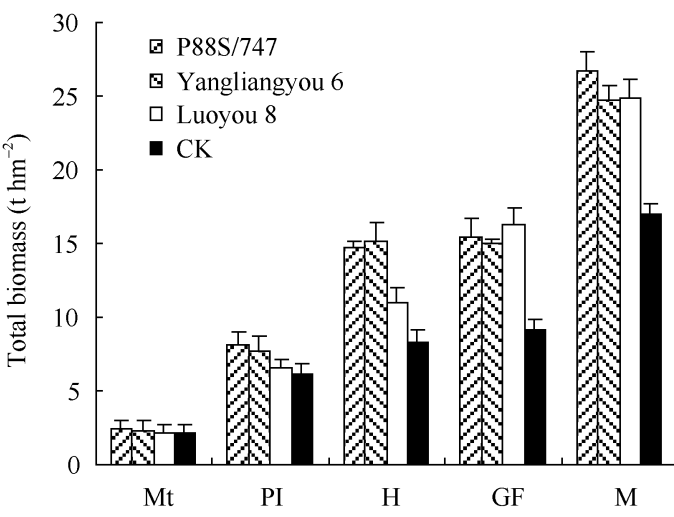

图 52008 年不同生育时期水稻总生物量

Fig. 5 Total biomass at the growth stage in rice in 2008 $\mathrm{Mt}$ : 分菜盛期; PI: 幼穗分化期; H: 齐穗期; GF：灌浆结实期; $\mathrm{M}$ : 成熟期。

Mt: mid-tillering stage; PI: panicle initiation stage; $\mathrm{H}$ : heading stage; GF: grain filling stage; M: maturity stage. 


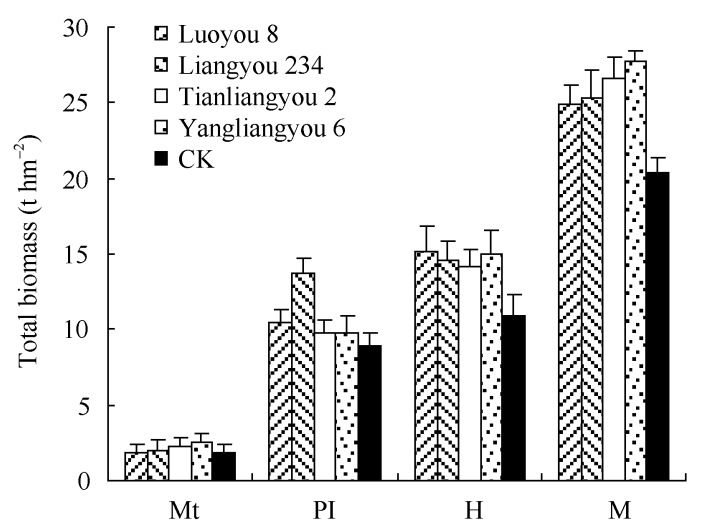

图 62009 年不同生育时期水稻总生物量

Fig. 6 Total biomass at the growth stage in rice in 2009 Mt: 分藍盛期; PI：幼穗分化期; H: 齐穗期; GF：灌浆结实期; $\mathrm{M}$ : 成熟期。

Mt: mid-tillering stage; PI: panicle initiation stage; H: heading stage; GF: grain filling stage; M: maturity stage.
8.5 9.5, 灌浆期为 9.5 10.0, 成熟期为 18.0 20.0, 齐穗前后所积累的总生物量各占成熟期总生物量的 $50 \%$ 左右。说明超高产栽培水稻中后期积累的生物 量远大于高产栽培水稻。

\section{5 养分 $(N 、 P 、 K)$ 含量}

超高产栽培水稻不同生育时期各器官的 N、P、 $K$ 含量与对照之间存在较大差异(表 2)。在水稻生长 的前中期(分菜期和幼穗分化期), 对照各器官的 $N$ 、

P、K 含量明显高于超高产栽培。分葟期, 对照茎叶 的 N、P、K 含量分别介于 $11.20 \sim 17.50 、 1.34 \sim 1.70$ 、 $4.80 \sim 16.47 \mathrm{~g} \mathrm{~kg}^{-1}$, 而超高产栽培水稻分别介于 12.69 16.10、1.09 2.34、10.56 17.80 $\mathrm{g} \mathrm{kg}^{-1}$ 和 15.78 24.90、0.83 1.61、5.00 10.10 $\mathrm{g} \mathrm{kg}^{-1}$ 。幼穗分 化期也表现出与分䅦期相同的趋势。齐穗期, 超高

表 2 不同处理各生育时期氮、磷、钾含量

Table $2 \mathrm{~N}, \mathrm{P}$, and $\mathrm{K}$ concentration in the organs at different growth stages $\left(\mathrm{g} \mathrm{kg}^{-1}\right)$

\begin{tabular}{|c|c|c|c|c|c|c|c|c|}
\hline $\begin{array}{l}\text { 生育时期 } \\
\text { Growth } \\
\text { stage }\end{array}$ & $\begin{array}{c}\text { 养分 } \\
\text { Nutrition }\end{array}$ & $\begin{array}{l}\text { 器官 } \\
\text { Organ }\end{array}$ & P88S/747 & $\begin{array}{c}\text { 扬两优 } 6 \\
\text { Yangliagnyou } 6\end{array}$ & $\begin{array}{c}\text { 珞优 } 8 \\
\text { Luoyou } 8\end{array}$ & $\begin{array}{c}\text { 两优 } 234 \\
\text { Liangyou } 234\end{array}$ & $\begin{array}{c}\text { 天两优 } 2 \\
\text { Tianliangyou } 2\end{array}$ & CK \\
\hline \multirow{6}{*}{$\begin{array}{c}\text { 分萆期 } \\
\text { Midtillering } \\
\text { stage }\end{array}$} & \multirow[t]{2}{*}{$\mathrm{N}$} & 茎 Stem & $13.07 \mathrm{~b}$ & $12.69 \mathrm{~b}$ & $13.10 \mathrm{~b}$ & $16.10 \mathrm{a}$ & $15.10 \mathrm{a}$ & $11.20 \mathrm{~b}$ \\
\hline & & 叶 Leaf & $22.28 \mathrm{a}$ & $19.80 \mathrm{~b}$ & $15.78 \mathrm{~b}$ & $24.50 \mathrm{a}$ & $24.90 \mathrm{a}$ & $17.50 \mathrm{~b}$ \\
\hline & \multirow[t]{2}{*}{$\mathrm{P}$} & 초 Stem & $1.09 \mathrm{~b}$ & $1.55 \mathrm{~b}$ & $1.13 \mathrm{~b}$ & $2.24 \mathrm{a}$ & $2.34 \mathrm{a}$ & $1.70 \mathrm{~b}$ \\
\hline & & 叶 Leaf & $0.92 \mathrm{a}$ & $1.00 \mathrm{a}$ & $0.83 \mathrm{a}$ & $1.45 \mathrm{a}$ & $1.61 \mathrm{a}$ & $1.34 \mathrm{a}$ \\
\hline & \multirow[t]{2}{*}{$\mathrm{K}$} & 茎 Stem & $10.56 \mathrm{~b}$ & $11.12 \mathrm{~b}$ & $14.40 \mathrm{ab}$ & $17.80 \mathrm{a}$ & $16.40 \mathrm{a}$ & $16.47 \mathrm{a}$ \\
\hline & & 叶 Leaf & $6.08 \mathrm{~b}$ & $5.46 \mathrm{~b}$ & $5.00 \mathrm{~b}$ & $10.08 \mathrm{a}$ & $10.10 \mathrm{a}$ & $4.80 \mathrm{~b}$ \\
\hline \multirow{6}{*}{$\begin{array}{c}\text { 幼穗分化期 } \\
\text { Panicle } \\
\text { initiation } \\
\text { stage }\end{array}$} & \multirow[t]{2}{*}{$\mathrm{N}$} & 茎 Stem & $4.11 \mathrm{~b}$ & $3.29 \mathrm{~b}$ & $4.50 \mathrm{~b}$ & $8.20 \mathrm{a}$ & $8.90 \mathrm{a}$ & $7.60 \mathrm{a}$ \\
\hline & & 叶 Leaf & $11.95 \mathrm{~b}$ & 15.24 a & $14.60 \mathrm{a}$ & $10.70 \mathrm{~b}$ & $11.50 \mathrm{~b}$ & $9.80 \mathrm{~b}$ \\
\hline & \multirow[t]{2}{*}{$\mathrm{P}$} & 茎 Stem & $1.19 \mathrm{a}$ & $1.32 \mathrm{a}$ & $1.26 \mathrm{a}$ & $1.15 \mathrm{a}$ & $1.24 \mathrm{a}$ & $1.53 \mathrm{a}$ \\
\hline & & 叶 Leaf & $0.82 \mathrm{a}$ & $1.05 \mathrm{a}$ & $1.06 \mathrm{a}$ & 0.83 a & 0.73 a & $0.82 \mathrm{a}$ \\
\hline & \multirow[t]{2}{*}{$\mathrm{K}$} & 茎 Stem & $7.53 \mathrm{a}$ & $8.00 \mathrm{a}$ & $8.80 \mathrm{a}$ & $8.78 \mathrm{a}$ & $7.30 \mathrm{a}$ & $5.30 \mathrm{~b}$ \\
\hline & & 叶 Leaf & $5.17 \mathrm{~b}$ & $4.90 \mathrm{~b}$ & $7.20 \mathrm{a}$ & $5.50 \mathrm{~b}$ & $6.10 \mathrm{ab}$ & $4.20 \mathrm{~b}$ \\
\hline \multirow{9}{*}{$\begin{array}{l}\text { 齐穗期 } \\
\text { Heading } \\
\text { stage }\end{array}$} & \multirow[t]{3}{*}{$\mathrm{N}$} & 茎 Stem & $7.90 \mathrm{a}$ & $5.55 \mathrm{a}$ & $7.70 \mathrm{a}$ & $5.70 \mathrm{a}$ & $8.30 \mathrm{a}$ & $6.90 \mathrm{a}$ \\
\hline & & 叶 Leaf & $19.10 \mathrm{a}$ & $12.68 \mathrm{~b}$ & $13.33 \mathrm{~b}$ & $13.40 \mathrm{~b}$ & $14.70 \mathrm{~b}$ & $7.50 \mathrm{c}$ \\
\hline & & 穗 Ear & $13.07 \mathrm{~b}$ & $17.33 \mathrm{a}$ & 16.60 a & $13.60 \mathrm{~b}$ & $12.20 \mathrm{~b}$ & $8.80 \mathrm{c}$ \\
\hline & \multirow[t]{3}{*}{$\mathrm{P}$} & 茎 Stem & $1.46 \mathrm{a}$ & $1.21 \mathrm{a}$ & $1.31 \mathrm{a}$ & $1.16 \mathrm{a}$ & $1.46 \mathrm{a}$ & $1.21 \mathrm{a}$ \\
\hline & & 叶 Leaf & $1.22 \mathrm{a}$ & $1.15 \mathrm{a}$ & $1.13 \mathrm{a}$ & $1.08 \mathrm{a}$ & $1.20 \mathrm{a}$ & $1.06 \mathrm{a}$ \\
\hline & & 穗 Ear & $1.24 \mathrm{a}$ & $1.14 \mathrm{a}$ & $1.17 \mathrm{a}$ & $0.95 \mathrm{a}$ & $0.99 \mathrm{a}$ & $1.36 \mathrm{a}$ \\
\hline & \multirow[t]{3}{*}{$\mathrm{K}$} & 茎 Stem & $15.80 \mathrm{ab}$ & $17.51 \mathrm{a}$ & $19.10 \mathrm{a}$ & $16.50 \mathrm{ab}$ & $13.30 \mathrm{~b}$ & $12.20 \mathrm{~b}$ \\
\hline & & 叶 Leaf & $8.29 \mathrm{c}$ & $12.58 \mathrm{~b}$ & $16.20 \mathrm{a}$ & $12.70 \mathrm{~b}$ & $17.10 \mathrm{a}$ & $7.88 \mathrm{c}$ \\
\hline & & 穗 Ear & $2.76 \mathrm{~b}$ & $3.48 \mathrm{~b}$ & $4.80 \mathrm{~b}$ & $9.00 \mathrm{a}$ & $9.20 \mathrm{a}$ & $5.45 \mathrm{~b}$ \\
\hline \multirow{6}{*}{$\begin{array}{c}\text { 成熟期 } \\
\text { Maturity } \\
\text { stage }\end{array}$} & \multirow[t]{2}{*}{$\mathrm{N}$} & 稻草 Straw & $5.37 \mathrm{a}$ & $6.68 \mathrm{a}$ & $4.40 \mathrm{a}$ & $7.60 \mathrm{a}$ & $5.30 \mathrm{a}$ & $4.50 \mathrm{a}$ \\
\hline & & 籽粒 Grain & $8.17 \mathrm{a}$ & $8.06 \mathrm{a}$ & $7.80 \mathrm{a}$ & $5.80 \mathrm{a}$ & $7.60 \mathrm{a}$ & $6.10 \mathrm{a}$ \\
\hline & \multirow[t]{2}{*}{$\mathrm{P}$} & 稻草 Straw & 0.43 a & $0.50 \mathrm{a}$ & $0.31 \mathrm{a}$ & $0.46 \mathrm{a}$ & $0.24 \mathrm{a}$ & $0.41 \mathrm{a}$ \\
\hline & & 籽粒 Grain & $1.37 \mathrm{a}$ & $1.22 \mathrm{a}$ & $1.44 \mathrm{a}$ & $1.22 \mathrm{a}$ & $1.41 \mathrm{a}$ & $1.19 \mathrm{a}$ \\
\hline & \multirow[t]{2}{*}{$\mathrm{K}$} & 稻草 Straw & $5.94 \mathrm{a}$ & $8.91 \mathrm{a}$ & $5.60 \mathrm{a}$ & $7.70 \mathrm{a}$ & $6.30 \mathrm{a}$ & $4.60 \mathrm{a}$ \\
\hline & & 籽粒 Grain & $1.97 \mathrm{a}$ & $1.98 \mathrm{a}$ & $1.80 \mathrm{a}$ & $1.83 \mathrm{a}$ & $1.70 \mathrm{a}$ & $1.99 \mathrm{a}$ \\
\hline
\end{tabular}

标明不同小写字母的值差异达 $5 \%$ 显著水平。

Values followed by different letters are significantly different at $5 \%$ probability level. 
产栽培水稻各器官的 $N 、 P 、 K$ 含量明显高于对照, 其 中叶片和穗中的 N、K 含量显著高于对照。超高产 栽培水稻茎叶穗的 N、P、K 含量分别介于 5.55 8.30、 1.16 1.46、13.30 19.10、12.68 19.10、1.08 1.22、 $8.29 \sim 17.10 \mathrm{~g} \mathrm{~kg}^{-1}$ 和 $12.20 \sim 17.33 、 0.95 \sim 1.24$ 、 2.76 9.20 $\mathrm{g} \mathrm{kg}^{-1}$, 而对照分别介于 $6.90 \sim 8.80$ 、 $1.06 \sim 1.36$ 和 $5.45 \sim 12.20 \mathrm{~g} \mathrm{~kg}^{-1}$ 。针对不同器官而言, 叶片 $\mathrm{N}$ 素含量较高, 而茎鞘的 $\mathrm{P} 、 \mathrm{~K}$ 含量较高。

\section{6 养分吸收积累特性}

超高产栽培水稻和对照在不同生育时期积累的 $\mathrm{N} 、 \mathrm{P} 、 \mathrm{~K}$ 养分总量存在较大差异。从表 3 可以看出, 超高产栽培水稻分菜期所积累的 $N 、 P 、 K$ 养分总量 与对照没有显著差异(珞优 8 号养分积累量显著低于 高产栽培), 其值分别介于 37.05 48.97、2.43 5.76 和 $18.47 \sim 30.57 \mathrm{~kg} \mathrm{hm}^{-2}$, 而对照分别为 $33.47 、 3.49$ 和 $23.97 \mathrm{~kg} \mathrm{hm}^{-2}$ 。幼穗分化期, 大多数超高产栽培 水稻(珞优 8 号除外)的 $\mathrm{P} 、 \mathrm{~K}$ 养分积累总量显著高于 对照, 其值分别介于 $65.70 ~ 83.58 、 8.36 \sim 9.27$ 和 $50.81 \sim 61.41 \mathrm{~kg} \mathrm{hm}^{-2}$, 而对照仅为 58.03、8.29 和 $31.57 \mathrm{~kg} \mathrm{hm}^{-2}$ 。齐穗期, 超高产栽培水稻 $\mathrm{N} 、 \mathrm{P} 、 \mathrm{~K}$ 养分积累速度较快, 养分积累总量也显著高于对照, 其值分别介于 92.05 100.72、12.15 15.64 kg hm 和 $127.83 \sim 156.42 \mathrm{~kg} \mathrm{hm}^{-2}$, 而对照仅为 56.19、7.87 和 $66.44 \mathrm{~kg} \mathrm{hm}^{-2}$ 。成熟期, 两种栽培模式水稻 $\mathrm{N} 、 \mathrm{P}$ 养分积累总量达到最大值, 而 $\mathrm{K}$ 积累总量有所降 低。超高产栽培水稻 $N 、 P 、 K$ 养分积累总量均显著
高于对照，其值分别介于 153.35 183.44、21.10 24.46 和 $90.01 \sim 130.83 \mathrm{~kg} \mathrm{hm}^{-2}$, 而对照仅为 96.35、 15.14 和 $55.90 \mathrm{~kg} \mathrm{hm}^{-2}$ 。从以上分析可以看出, 与对 照相比, 超高产栽培水稻(产量 $>12 \mathrm{thm}^{-2}$ ) 在 N、P、 $\mathrm{K}$ 养分吸收上具有总吸收量高、生长前期(分藍期) 与对照差异较小、生长中后期(幼穗分化期以后)特 别是幼穗分化期至齐穗期吸收比例高的特点。

\section{3 讨论}

\section{1 超高产杂交中籼稻产量形成特点}

大幅度地扩大产量库容(增加总颖花量)是实现 水稻超高产的前提 ${ }^{[3,13]}$ 。Sheehy 等 ${ }^{[14]}$ 研究认为, 水稻 获得超高产的关键在于大幅度增加每穗粒数。杨建 昌等 ${ }^{[15]}$ 研究认为, 粳型水稻超高产栽培技术途径是 在一定穗数的基础上, 通过主攻大穗扩大库容。而 吴文革等 ${ }^{[16]}$ 研究认为, 培育大穗是超高产栽培水稻 扩大库容量、增加颖花量的主要途径。大穗的形成 主要是通过增加一次枝梗数和二次枝梗数及其平均 着粒数，通过优化一、二次枝梗上颖花分布来提高 结实率从而增加单穗重和最终产量。本研究结果表明, 与对照(产量 $\geqslant 9.0 \mathrm{t} \mathrm{hm}^{-2}$ )相比, 超高产栽培水稻(产 量 $\geqslant 12.0 \mathrm{t} \mathrm{hm}{ }^{-2}$ )虽然每穗粒数有所增加, 但总颖花 量的增加主要依靠单位面积的穗数。超高产栽培水 稻单位面积有效穗数均超过 $250 \times 10^{4}$ 穗 $\mathrm{hm}^{-2}$, 而对照 (高产水稻)仅为 $200 \times 10^{4} \sim 220 \times 10^{4}$ 穗 $\mathrm{hm}^{-2}$ 。在适宜 高峰苗的基础上，提高水稻的成穗率，确保足穗。在

表 3 不同处理各生育时期氮、磷、钾积累总量

Table 3 Total N, P, and $\mathbf{K}$ accumulation at different growth stages $\left(\mathrm{kg} \mathrm{hm}^{-2}\right)$

\begin{tabular}{cccccrcc}
\hline $\begin{array}{c}\text { 生育时期 } \\
\text { Growth stage }\end{array}$ & $\begin{array}{c}\text { 养分 } \\
\text { Nutrition }\end{array}$ & P88S/747 & $\begin{array}{c}\text { 扬两优 6 } \\
\text { Tianliangyou 6 }\end{array}$ & $\begin{array}{c}\text { 珞优 8 号 } \\
\text { Luoyou 8 }\end{array}$ & $\begin{array}{c}\text { 两优 234 } \\
\text { Liangyou 234 }\end{array}$ & $\begin{array}{c}\text { 天两优 2 } \\
\text { Tianliangyou 2 }\end{array}$ & CK \\
\hline 分䔒期 & $\mathrm{N}$ & $43.76 \mathrm{a}$ & $37.05 \mathrm{ab}$ & $27.31 \mathrm{~b}$ & $48.97 \mathrm{a}$ & $46.85 \mathrm{a}$ & $33.47 \mathrm{ab}$ \\
Mid-tillering stage & $\mathrm{P}$ & $2.43 \mathrm{c}$ & $2.86 \mathrm{bc}$ & $2.01 \mathrm{c}$ & $3.58 \mathrm{~b}$ & $5.76 \mathrm{a}$ & $3.49 \mathrm{~b}$ \\
& $\mathrm{~K}$ & $20.01 \mathrm{~b}$ & $18.47 \mathrm{~b}$ & $15.31 \mathrm{~b}$ & $27.71 \mathrm{a}$ & $30.57 \mathrm{a}$ & $23.97 \mathrm{ab}$ \\
幼穗分化期 & $\mathrm{N}$ & $65.70 \mathrm{~b}$ & $68.82 \mathrm{~b}$ & $55.96 \mathrm{c}$ & $70.94 \mathrm{~b}$ & $83.58 \mathrm{a}$ & $58.03 \mathrm{c}$ \\
Panicle initiation & $\mathrm{P}$ & $8.27 \mathrm{a}$ & $9.27 \mathrm{a}$ & $7.58 \mathrm{~b}$ & $8.36 \mathrm{a}$ & $9.27 \mathrm{a}$ & $8.29 \mathrm{a}$ \\
stage & $\mathrm{K}$ & $52.20 \mathrm{a}$ & $50.81 \mathrm{a}$ & $34.05 \mathrm{~b}$ & $61.41 \mathrm{a}$ & $59.46 \mathrm{a}$ & $31.57 \mathrm{~b}$ \\
齐穗期 & $\mathrm{N}$ & $98.72 \mathrm{a}$ & $92.05 \mathrm{a}$ & $70.82 \mathrm{~b}$ & $92.16 \mathrm{a}$ & $100.72 \mathrm{a}$ & $56.19 \mathrm{~b}$ \\
Heading stage & $\mathrm{P}$ & $15.64 \mathrm{a}$ & $12.77 \mathrm{~b}$ & $9.92 \mathrm{c}$ & $12.15 \mathrm{~b}$ & $13.97 \mathrm{ab}$ & $7.87 \mathrm{c}$ \\
& $\mathrm{K}$ & $145.16 \mathrm{a}$ & $148.85 \mathrm{a}$ & $91.73 \mathrm{~b}$ & $156.42 \mathrm{a}$ & $127.83 \mathrm{ab}$ & $66.44 \mathrm{c}$ \\
成熟期 & $\mathrm{N}$ & $182.53 \mathrm{a}$ & $183.44 \mathrm{a}$ & $153.35 \mathrm{~b}$ & $168.84 \mathrm{~b}$ & $163.73 \mathrm{~b}$ & $96.35 \mathrm{c}$ \\
Maturity stage & $\mathrm{P}$ & $24.46 \mathrm{a}$ & $21.67 \mathrm{a}$ & $22.32 \mathrm{a}$ & $21.68 \mathrm{a}$ & $21.10 \mathrm{a}$ & $15.14 \mathrm{~b}$ \\
& $\mathrm{~K}$ & $103.91 \mathrm{ab}$ & $130.83 \mathrm{a}$ & $90.01 \mathrm{~b}$ & $117.69 \mathrm{a}$ & $100.46 \mathrm{ab}$ & $55.90 \mathrm{c}$ \\
\hline
\end{tabular}

标明不同小写字母的值差异达 $5 \%$ 显著水平。

Values followed by different letters are significantly different at $5 \%$ probability level. 
一定穗数 (足穗) 基础上, 通过主攻大穗和提高结 实率扩大库容, 才能够更容易获得水稻的超高产 栽培。

\section{2 超高产杂交中籼稻的干物质积累特性}

水稻产量形成过程实质上就是干物质积累与分 配的过程。稻谷产量即生物产量和收获指数的乘积, 因此, 提高生物产量或收获指数均可提高稻谷产 量。在收获指数达到极限值的情况下, 生物量的提 高则是实现水稻超高产栽培的主要途径 ${ }^{[17-21]}$ 。吴文 革等 ${ }^{[22]}$ 研究发现, 超高产栽培水稻的干物质积累优 势在中、后期。凌启鸿 ${ }^{[3]}$ 研究认为, 超高产栽培水稻 抽穗期的干物质积累量占成熟期总干重的 60\%左右, 抽穗至成熟期积累的干物重约占总干物质重的 $40 \%$ 。本研究结果表明, 超高产栽培水稻生长前期 (分菜期和幼穗分化期)干物质积累量与高产栽培水 稻相接近, 但是, 进入幼穗分化期以后, 超高产栽 培水稻的干物质积累量显著高于高产栽培。这主要 是因为超高产栽培水稻基施氮肥较少, 水稻生长前 期长势平稳, 高峰苗适中, 后期增加穗粒肥的施用, 增加了水稲的叶面积指数和高效叶面积的比率, 提 高了叶片的光合速率和根系活力, 促进了水稻干物 质的积累和养分的吸收利用 ${ }^{[23-25]}$ 。

\section{3 超高产杂交中籼稻的养分吸收特性}

已有研究表明, 超高产栽培水稻具有产量水平 高, 干物质积累多, 根系活力强, 对养分的吸收利 用也较多的特点, 因此, 增加了对 N、P、K 养分的 需求量, 特别是对 $P 、 K$ 的需求比例 ${ }^{[26-28]}$ 。本研究结 果表明, 超高产栽培水稻品种(珞优 8 号除外)分菜盛 期对 N、P、K 养分吸收利用优势不明显, 茎叶等器 官的 N、 $P 、 K$ 养分含量与对照持平或略低于对照, 而 幼穗分化期、齐穗期和成熟期对 N、P、K 养分吸收 利用显著高于高产栽培, 茎叶穗等器官中的养分含 量也明显高于对照, 这主要与肥料运筹策略和水稻 群体大小密切相关。前者产量的增加主要在于生物 产量的增加, 而形成较强大的生物产量, 需要较多 的养分吸收量。在生育前期, 由于超高产栽培下基 肥的氮素用量相对较少, 稻株的含氮量和群体的生 长量均较低, 无效分菜较少。反映在养分吸收特性 上, 超高产水稻生育前期氮素的养分吸收量低于常 规高产栽培, 而在生育中后期特别是拔节至抽穗期 超高产水稻的养分吸收的比例高, 与其穗肥的施用 量或施用比例高有密切关系。

3.4 超高产杂交中籼稻的关键栽培技术

近些年来，针对不同生态区域和种植制度，提
出了一些水稻超高产栽培关键技术 ${ }^{[8-9,29]}$ 。他们分别 从育种、施肥和防治病虫害等方面进行了深入研究, 对水稻的高产栽培起到了很好的推动作用。与以往 的水稻超高产栽培技术相比, 本试验的超高产栽培 技术, 主要针对茬口(上季作物为小麦、大麦和油菜) 较短, 秧龄较长的杂交中籼稻种植地区, 首先依据 品种自身的穗型特征，明确产量提高的主攻方向， 通过培育“壮”积和插“足”基本苗，确保水稻高产所 需要的“足”穗，在保证“足”穗的基础上，适当增加 水稻生长后期粒肥和花肥的施用量, 确保水稻生长 后期仍然具有较大的叶面积指数和较高的高效叶面 积比率, 增强水稻生长后期根系活力, 提高水稻的 结实率和千粒重而形成“大”穗和“饱”粒，从而获取 水稻的超高产, 而对照之所以产量不高, 主要是因 为秧龄过长, 水稻有效分藍期缩短, 有效分藍减少, 栽插密度又较小, 导致最后的穗数严重不足, 氮肥 的施用主要集中于前期(底肥和分藮肥), 水稻的结 实率不高和籽粒不饱满。而针对不同穗型特征的水 稻品种和生态区域的超高产栽培, 还需要进一步深 入研究。

\section{4 结论}

与高产(产量 $\geqslant 9.0 \mathrm{t} \mathrm{hm}{ }^{-2}$ )水稻相比, 超高产(产 量 $\geqslant 12.0 \mathrm{t} \mathrm{hm}^{-2}$ )水稻在叶面积指数(LAI)方面, 前期 LAI 适中, 分葟盛期为 3.0 3.5 左右; 中后期 LAI 大, 幼穗分化期为 6.5 7.2, 齐穗期为 8.5 8.9, 灌浆期 (齐穗后 $10 \mathrm{~d}$ )为 $6.5 \sim 7.0$ 。而且, 齐穗期高效叶面积 比率高，为 $60.0 \%$ 66.5\%。干物质积累方面 $\left(\mathrm{t} \mathrm{hm}^{-2}\right)$, 中后期积累较多的干物质, 齐穗期为 13.5 15.0, 灌 浆期为 15.0 16.0, 成熟期为 25.0 28.0。养分吸收利 用方面，分菜盛期对 N、P、K 吸收利用优势不明显， 而幼穗分化期、齐穗期和成熟期对 N、P、K 吸收 利用高且积累速度快。产量构成方面, 具有穗数多 (有效穗数介于 $250 \times 10^{4} \sim 290 \times 10^{4}$ 穗 $\mathrm{hm}^{-2}$ )、结实率 高(88.2\% 92.3\%)和千粒重大(29.0 31.0 g)的特点。

\section{References}

[1] National Bureau of Statistics of China. China National Statistics Yearbook in 2006 (2006 年国家统计年鉴). Beijing: National Statistics Press, 2006 (in Chinese)

[2] Yuan L-P(袁隆平). Super-high-yield breeding in hybrid rice. Hybrid Rice (杂交水稻), 2000, 15: 31-33 (in Chinese)

[3] Ling Q-H(凌启鸿). Quality of Crop Population (作物群体质量). Shanghai: Shanghai Scientific and Technical Publishers, 2000. pp 42-120 (in Chinese)

[4] Cheng S-H(程式华), Cao L-Y(曹立勇), Chen S-G(陈深广), Zhu 
D-F(朱德峰), Wang X(王喜), Min S-K(闵绍楷), Zhai H-Q(翟虎 渠). Conception of late-stage vigor super hybrid rice and its biological significance. Chin J Rice Sci (中国水稻科学), 2005, 19(3): 280-284 (in Chinese with English abstract)

[5] Zhu D-F(朱德峰). Cultivation Technique of Super High Yield Rice (超高产水稻栽培技术). Beijing: Jindun Press, 2006 (in Chinese)

[6] Dingkuhn M, Penning de Vries FWT, De Datta S K. Concepts for a New Plant Type for Direct Seeded Flooded Tropical Rice. Direct Seeded Flooded Rice in the Tropics. Los Banos, Philippines: Int Rice Res Inst, 1991. pp 17-38

[7] Ling Q-H(凌启鸿), Su Z-F(苏祖芳), Zhang H-Q(张海泉). Relationship between earbearing tiller percentage and population quality and its influential factors in rice. Acta Agron Sin (作物学 报), 1995, 21(5): 463-469 (in Chinese with English abstract)

[8] Ma J(马均), Tao S-S(陶诗顺). Study on the practice and high-yielding mechanism of super-sparse-cultivation associated with maximum-tiller seedling of hybrid rice. Sci Agric Sin (中国 农业科学), 2002, 35(1): 42-48(in Chinese with English Abstract)

[9] Zhong X-H(钟旭华), Huang N-R(黄农荣), Zheng H-B(郑海波), Peng S-B(彭少兵), Buresh R J. Specification for the “Three Controls” nutrient management technology for irrigated rice. Guangdong Agric Sci (广东农业科学), 2007, (5): 13-17 (in Chinese with English Abstract)

[10] Zou Y-B(邹应斌), Ao H-J(敖和军), Wang S-H(王淑红), Tang Q-Y(唐启源). Studies on San-Ding cultivation method for super rice: I. The concept and the principle. Chin Agric Sci Bull (中国 农学通报), 2006, 22(5): 158-162 (in Chinese with English Abstract)

[11] Bao S-D(鲍士旦). Soil Agriculture Chemistry Analysis (土壤农 化分析). Beijing: Chinese Agriculture Press, 2000 (in Chinese)

[12] Huang J L, He F, Cui K H, Buresh R J, Xu B, Gong W H, Peng S B. Determination of optimal nitrogen rate for rice varieties using a chlorophyll meter. Field Crops Res, 2008, 105: 70-80

[13] Ao H-J(謷和军), Wang S-H(王淑红), Zou Y-B(邹应斌), Peng S-B(彭少兵), Tang Q-Y(唐启源), Fang Y-X(方远祥), Xiao A-M(肖安民), Chen Y-M(陈玉梅), Xiong C-M(熊昌明). Study on yield stability and dry matter characteristics of super hybrid rice. Sci Agric Sin (中国农业科学), 2008, 41(7): 1927-1936 (in Chinese with English abstract)

[14] Sheehy J E, Dionora M J A, Mitchell P L. Spikelet numbers, sink size and potential yield in rice. Field Crops Res, 2001, 71: 77-85

[15] Yang J-C(杨建昌), Du-Y(杜永), Wu C-F(吴长付), Liu L-J(刘立 军), Wang Z-Q(王志琴), Zhu Q-S(朱庆森). Growth and development characteristics of super-high-yielding mid-season japonica rice. Sci Agric Sin (中国农业科学), 2006, 39(7): 1336-1345 (in Chinese with English abstract)

[16] Wu W-G(吴文革), Zhang H-C(张洪程), Wu G-C(吴桂成), Zhai C-Q(翟超群), Qian Y-F(钱银飞), Chen Y(陈烨), Xu J(徐军), Dai $\mathrm{Q}-\mathrm{G}($ 戴其根), Xu K(许轫). Preliminary study on super rice population sink characters. Sci Agric Sin (中国农业科学), 2007, 40(2): 250-257(in Chinese with English abstract)

[17] Du Y(杜永), Wang Y(王艳), Wang X-H(王学红), Sun N-L(孙乃 立), Yang J-C(杨建昌). Comparisons of plant type grain yield and quality of different japonica rice cultivars in HuangheHuaibei River area. Acta Agron Sin (作物学报), 2007, 33(7):
1079-1085 (in Chinese with English abstract)

[18] Zhai H-Q(翟虎渠)，Cao S-Q(曹树青)，Wan J-M(万建民)，Lu W(陆巍), Zhang R-X(张荣铣), Li L-B(李良壁), Kuang T-Y(匡 廷云), Min S-K(闵绍楷), Zhu D-F(朱德峰), Cheng S-H(程式华) Relationship between yield and photosynthesis efficiency at grain filling stage in hybrid rice. Sci China (Ser C)(中国科学·C 辑), 2002, 32(3): 211-217 (in Chinese)

[19] Yuan P-R(袁平荣), Sun C-Q(孙传清), Yang C-D(杨从党), Zhou-N(周能), Ying J-F(应急峰), Peng S-B(彭少兵), He Q-R(贺 庆瑞), Wang X-K(王象坤). Analysis on grain yield and yield components of the $15 \mathrm{t} \mathrm{ha}^{-1}$ high yielding indica rice (Oryza sativa L.) in Yunnan. Acta Agron Sin (作物学报), 2000, 26(6): 756-762 (in Chinese with English abstract)

[20] Katsura K, Maeda S, Lubis I, Horie T, Cao W X, Shiraiwa T. The high yield of irrigated rice in Yunnan, China 'A cross-location analysis'. Field Crops Res, 2008, 107: 1-11

[21] Yang H-J(杨惠杰), Li Y-Z(李义珍), Yang R-C(杨仁崔), Jiang Z-W(姜照伟), Zheng J-S(郑景生). Dry matter production characteristics of super high yielding rice. Chin J Rice Sci (中国水稻 科学), 2001, 15(4): 265-270 (in Chinese with English abstract)

[22] Wu W-G(吴文革), Zhang H-C(张洪程), Qian Y-F(钱银飞), Chen Y(陈烨), Xu-J(徐军), Wu G-C(吴桂成), Zhai C-Q(翟超群), Huo $\mathrm{Z}-\mathrm{Y}$ (霍中洋), Dai Q-G(戴其根). Analysis on dry matter production characteristics of middle-season indica super hybrid rice. Chin J Rice Sci (中国水稻科学), 2007, 21(3): 287-293 (in Chinese with English abstract)

[23] Xue Y-G(薛亚光), Chen T-T(陈婷婷), Yang C(杨成), Wang Z-Q(王志琴), Liu L-J(刘立军), Yang J-C(杨建昌). Effects of different cultivation patterns on the yield and physiological characteristics in mid-season japonica rice. Acta Agron Sin (作物学 报), 2010, 36(3): 466-476 (in Chinese with English abstract)

[24] Jiang L G, Dong D F, Gan X Q, Wei S Q. Photosynthetic efficiency and nitrogen distribution under different nitrogen management and relationship with physiological N-use efficiency in three rice genotypes. Plant Soil, 2005, 271: 321-328

[25] Wei H-Y(魏海燕), Zhang H-C(张洪程), Dai Q-G(戴其根), Huo Z-Y(霍中洋), Xu K(许轫), Hang J(杭杰), Ma Q(马群), Zhang S-F(张胜飞), Zhang Q(张庆), Liu Y-Y(刘艳阳). Characteristics of matter production and accumulation in rice genotypes with different N use efficiency. Acta Agron Sin (作物学报), 2007, 33(11): 1802-1809 (in Chinese with English abstract)

[26] Du Y(杜永), Liu H(刘辉), Yang C(杨成), Wang Z-Q(王志琴), Yang J-C(杨建昌). Characteristics of nutrient absorption in super-high-yielding mid-season and late-maturity japonica rice. Sci Agric Sin (中国农业科学), 2007, 33(2): 208-215 (in Chinese with English abstract)

[27] Ntanos D A, Koutroubas S D. Dry matter and N accumulation and translocation for indica and japonica rice under Mediterranean conditions. Field Crops Res, 2002, 74: 93-101

[28] Yang J-C(杨建昌), Wang P(王朋), Liu L-J(刘立军), Wang Z-Q(王志琴), Zhu Q-S(朱庆森). Evolution characteristics of grain yield and plant type for mid-season indica rice cultivars. Acta Agron Sin (作物学报), 2006, 32(7): 949-955 (in Chinese with English abstract)

[29] Yuan L-P(袁隆平). The system of rice intensification (SRI). Hybrid Rice (杂交水稻), 2001, 16(4): 1-3 (in Chinese) 